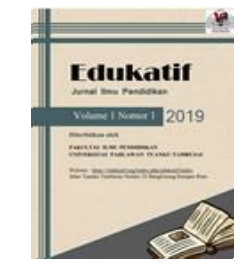

\title{
Pengembangan Media Pembelajaran Video Instruksional Interaktif Pada Mata Pelajaran Ekonomi
}

\author{
Kiranda Yuni Setyoningtyas ${ }^{1 凶}$, Muhammad Abdul Ghofur $^{2}$ \\ Universitas Negeri Surabaya, Indonesia ${ }^{1,2}$ \\ E-mail : kiranda.17080554028@ mhs.unesa.ac.id ${ }^{1}$, muhammadghofur@unesa.ac.id ${ }^{2}$
}

\begin{abstract}
Abstrak
Media pembelajaran berbasis video interaktif sangat bermanfaaat pada peningkatan hasil belajar pserta didik. Penelitian ini bertujuan untuk mengembangkan media pembelajaran dalam upaya meningkatkan pemahaman peserta didik mengenai materi ekonomi cirular diagram flow. Penelitian dan pengembangan (R\&D) dengan model Plomp dipilih sebagai jenis penelitian yang dikembangkan. Uji coba terbatas menggunakan desain One Group Pre-test-Post-test. Hasil uji coba terbatas sebagai bagian dari fase pengembangan telah mendapatkan hasil yang diharapkan. Terdapat perbedaan pemahaman sebagai hasil belajar oleh peserta didik.Media pembelajaran yang dikembangkan berperan sebagai media belajar mandiri, recalling, dan mendorong proses inkuiri.
\end{abstract}

Kata Kunci: media pembelajaran, video interaktif, circular diagram flow.

\begin{abstract}
Interactive video-based learning media is very useful in improving student learning outcomes. This study aims to develop learning media in an effort to improve students' understanding of circular flow diagram economics. Research and development $(R \& D)$ with the Plomp model was chosen as the type of research developed. The limited trial using One Group Pre-test-Post-test design. The results of the limited trial as part of the development phase have achieved the expected results. There are differences in understanding as a result of learning by students. The developed learning media acts as a medium for independent learning, recalling, and encouraging the inquiry process.
\end{abstract}

Keywords: learning media, interactive video, circular diagram flow

Copyright (c) 2021 Kiranda Yuni Setyoningtyas, Muhammad Abdul Ghofur

$\triangle$ Corresponding author:

Email : kiranda.17080554028@mhs.ac.id

DOI : https://doi.org/10.31004/edukatif.v3i4.601

ISSN 2656-8063 (Media Cetak)

ISSN 2656-8071 (Media Online)

Edukatif : Jurnal Ilmu Pendidikan Vol 3 No 4 Tahun 2021 p-ISSN 2656-8063 e-ISSN 2656-8071 
1522 Pengembangan Media Pembelajaran Video Instruksional Interaktif Pada Mata Pelajaran Ekonomi Kiranda Yuni Setyoningtyas, Muhammad Abdul Ghofur

DOI: https://doi.org/10.31004/edukatif.v3i4.601

\section{PENDAHULUAN}

Prinsip ekonomi mempengaruhi semua orang dan segala sesuatu dalam kehidupan sehari hari. Beberapa negara mengakui pentingnya mempelajari literasi ekonomi guna memahami sistem ekonomi dunia bekerja (Marks \& Kotula, 2009). Dimana pasar bebas merupakan faktor penting dalam sistem perekonomian dunia saat ini, dalam dunia pendidikan pasar bebas ekonomi direpresentasikan sebagai circular flow diagram yang wajib dipelajari di setiap sekolah menengah atas (Daraban, 2010). Circular flow diagram berisi tentang berbagai konsep penting dalam ekonomi seperti konsumen, produsen, sumber daya perdagangan/pertukaran, barang layanan, dan uang. Hal ini sangat berkaitan dengan empat sektor mengenai pendapatan nasional (Marks \& Kotula, 2009). Pembelajaran mengenai circular flow diagram memiliki tujuan agar peserta didik memiliki keterampilan untuk menalar, memahami konsep circular flow diagram dan juga untuk memberikan keterampilan dalam membuat bagan interaksi antar pelaku kegiatan ekonomi yang ada pada circular flow diagram (Revangga, 2015).

Jika dilihat dari segi materinya circular flow diagram membutuhkan banyak visualisasi pada proses gerak yang terjadi antara sektor satu dengan yang lainnya (Furi, U. L., \& Mustaji, 2017). Sebuah studi awal dilakukan di SMA Muhammadiyah Nganjuk guna mengetahui proses pembelajaran ekonomi berlangsung. Hasilnya ditemukan beberapa kendala untuk memahamkan peserta didik khususnya pada materi circular flow diagram, dimana peserta didik sulit menggambarkan proses kegiatan ekonomi. Meskipun pengajar telah memberikan contoh dan menjelaskan dengan detail peserta didik cenderung bingung ketika diperintahkan untuk menggambarkan kembali circular flow diagram ataupun menjawab soal yang berkaitan dengan materi. Jika dilihat dari kesehariannya peserta didik cenderung banyak bergerak selama proses belajar dan akan mudah bosan ketika pembelajaran hanya berisi penjelasan. Sehingga gaya belajar peserta didik ini bisa dikategorikan sebagai gaya belajar kinestetik. Pengembangan media pembelajaran diperlukan untuk bisa melibatkan peserta didik selama prosesnya . Dari sini data disimpulkan bahwa permasalahan peserta didik dalam memahami materi circular diagram flow ialah kesulitan dalam menggambarkan proses yang ada pada materi tersebut serta kurangnya keterlibatan peserta didik di dalam pembelajaran.

Pengalaman langsung, pengalaman piktorial, dan pengalaman abstrak merupakan tingkatan dalam pembelajaran (Arsyad, 2011). Pengalaman langsung bermakna adanya keterlibatan aktif antara peserta didik dengan proses pembelajaran yang tengah berlangsung. Pada pengalaman piktoral peserta didik mempelajari sesuatu berdasarkan gambar, foto maupun video. Membaca atau mendengarkan uraian materi merupakan pemahaman yang didapatkan melalui pengalaman abstrak (Sukiman, 2012).

Untuk menyampaikan pesan pembelajaran biasanya guru/pendidik menggunakan media sebagai sarana belajar (Arsyad, 2011). Sementara menurut Anderson, untuk memungkinkan terwujudnya hubungan langsung guru dengan peserta didik akan lebih baik menggunakan media pembelajaran sebagai perantara atau pendamping belajar. Pembelajaran daring dengan menggunakan video juga membuat peserta didik lebih aktif, walaupun dengan karakter dan hasil belajar yang berbeda-beda (Yoon et al., 2021). Media pembelajaran membantu transfer ilmu dari pengajar kepada peserta didik. Namun, penggunaan media pembelajaran terutama berbasis video masih sangat minim dan jarang diterapkan pada mata pelajaran ekonomi setingkat sekolah menengah atas (Marks \& Kotula, 2009).

Pada materi ekonomi circular flow diagram telah banyak digunakan media pembelajaran dan model pembelajaran seperti role playing (Hafizh, 2017), di Semarang pembelajaran dengan materi circular flow diagram menggunakan media sosiodrama (Maulidiyah, 2018), di SMAN 1 Sewon kelas X MA 4 materi circular diagram flow menggunakan model pembelajaran Game Tournament (TGT). Jika dilihat lebih jauh penggunaan media pembelajaran masih kurang maksimal terutama penggunaan video (Marks \& Kotula, 2009). Sebagaimana yang dikatakan oleh Bruner tingkatan seorang pelajar adalah pengalaman langsung, 
1523 Pengembangan Media Pembelajaran Video Instruksional Interaktif Pada Mata Pelajaran Ekonomi Kiranda Yuni Setyoningtyas, Muhammad Abdul Ghofur

DOI: https://doi.org/10.31004/edukatif.v3i4.601

pengalaman gambar, pengalaman abstrak. Dimana beberapa pengalaman ini bisa diraih salah satunya dapat dicapai melalui pembelajaran berbasis video.

Pada materi kegiatan ekonomi dengan sub materi circular diagram flow diketahui bahwa materi memiliki karakteristik yang membutuhkan visualisasi menarik, serta dapat menjelaskan proses gerak pada arus kegiatan (circular diagram flow). Beberapa media pembelajaran digunakan untuk mendukung proses belajar peserta didik, salah satunya yakni media berbasis video. Video memiliki kemampuan untuk menyajikan informasi, menggambarkan suatu proses, mengajarkan keterampilan, serta dapat diulang (Agustriana et al., 2014).

Penggunaan media pembelajaran berbasis video mampu mendemonstrasikan bagaimana melakukan prosedur seperti matematika komputasi, tugas manipulasi tangan sebagaimana video Do-It-Yourself (ten Hove, P., \& van der Meij, 2015). Perusahaan manufaktur seperti Ikea juga menggunakan media video untuk dapat menjelaskan proses merakit suatu barang (Ikea, 2017). Beberapa situs web seperti Lynda, Adobe, Microsoft dan TechSmith juga menggunakan media video sebagai bahan pelatihan perangkat lunak, mereka menggabungkan rekaman layar animasi dengan narasi lisan.

Untuk menjelaskan proses kegiatan ekonomi makro, Universitas Seville (Spanyol) menggunakan media klip video dan berhasil meningkatkan nilai tes mahasiswanya menjadi lebih tinggi (Expósito et al., 2020). Pada sebuah hasil penelitian ilmiah yang berjudul "Penggunaan Media Video Dalam Pembelajaran Ekonomi Studi Eksperimen SMA" menyatakan bahwa media pembelajaran berupa video dapat diterapkan di seluruh lingkungan pengajaran (Imaniya et al., 2016). Beberapa keunggulan media pembelajaran berbasis video ialah mampu menunjukkan keefektifan pembelajaran melalui visualisasi materi dalam berbagai disiplin ilmu termasuk di antaranya ekonomi (Fleck et al., 2013). Video pembelajaran telah banyak disorot karena memungkinkan proses pembelajaran yang lebih ringkas, serta dapat membentuk kemandirian peserta didik dalam belajar (Whatley \& Ahmad, 2007).

Video instruksional merupakan salah satu media pembelajaran yang mampu menjelaskan proses gerak dengan baik (Whatley \& Ahmad, 2007). Selain mampu mendemonstrasikan bagaimana melakukan prosedur (ten Hove, P., \& van der Meij, 2015). Video instruksional mampu menciptakan pengulangan yang dapat membantu pengguna memisahkan pesan pembelajaran (Obagah \& Brisibe, 2017). Media pembelajaran berbasis video dikategorikan sebagai salah satu media pembelajaran yang passive serta memiliki tingkat keabstrakan sebesar 50\%, yang mana menunjukkan keterbatasan dalam melibatkan indra, hanya pada pendengaran dan penglihatan (Sukiman, 2012). Pada sebuah penelitian mengenai penggunaan media video memang dapat meningkatkan kemandirian belajar akan tetapi tidak pada penilaian pemahaman mereka (Singer, L. M., \& Alexander, 2017). Hal ini dikarenakan peserta didik cenderung pasif dan tidak terlibat dalam pembelajaran (Agustriana et al., 2014). Dari sini memungkinkan peserta didik merasa jenuh dan tidak memperhatikan.

Penambahan tombol interaktif diharapkan membuat pengembangan media video ini menjadi berbeda dibandingkan penelitian - penelitian yang ada dan mampu melibatkan peserta didik sehingga menjadikan media ini sebagai multimedia instruksional interaktif. Multimedia interaktif merupakan media pembelajaran yang didesain dengan menambahkan alat kontrol yang memungkinkan penggunanya memilih suatu hal yang ia kehendaki (Diah \& Nita, 2018). Multimedia interaktif juga dirancang untuk mengarahkan perhatian peserta didik agar tetap fokus pada materi, selain itu peserta didik juga bisa berinteraksi langsung dengan proses pembelajaran di kelas (Sudarman, Sugeng, 2018). Multimedia interaktif yang akan dikembangkan dalam bentuk video dimana peserta didik dapat memahami proses cirular diagram flow juga menjawab soal latihan yang disediakan melalui $C D$ yang bisa diputar di perangkat seperti komputer. Tujuan pembuatan video difokuskan pada konsep materi cirular diagram flow memungkinkan video akan berdampak positif pada tugas pembelajaran langsung (Tarchi et al., 2021). 
1524 Pengembangan Media Pembelajaran Video Instruksional Interaktif Pada Mata Pelajaran Ekonomi Kiranda Yuni Setyoningtyas, Muhammad Abdul Ghofur

DOI: https://doi.org/10.31004/edukatif.v3i4.601

Pengembangan media pembelajaran pada materi ekonomi sejatinya bukan hal yang baru. Sebuah penelitian mengembangkan media berbasis power point pada materi ekonomi jurnal penyesuaian perusahaan jasa (Yuliandari, Sintia \& Wahyudi, 2014). Peneliti lain juga mengembangkan media berbasis android pada mata pelajaran ekonomi (Alhafidz et al., 2018). Namun, pengembangan pada media video masih tergolong baru. Meski telah banyak video pembelajaran yang tersebar di berbagai web atau platform seperti Youtube, namun video yang interaktif masih jarang ditemukan.

Jadi, pembelajaran mandiri menggunakan video interaktif dapat mendorong siswa yang aktif untuk lebih memperluas proses inkuirinya dengan melakukan aktivitas sosial, pencarian informasi lebih lanjut, dan mengonfigurasi lingkungan. Sedangkan siswa yang pasif masih terdorong keterlibatannya dalam melakukan pencarian informasi (Yoon et al., 2021). Preferensi sumber belajar peserta didik sekolah menengah atas juga semakin mengarah ke pembelajaran video (Ghofur \& Wahjoedi, 2018). Sehingga media pembelajaran berbasis video interaktif yang dapat merangsang proses inkuiri dan self-directed learning ini penting untuk dikembangkan.

Perbedaan dengan media pembelajaran yang telah ada sebelumnya yakni pada media yang akan dikembangkan oleh peneliti ini menggunakan tombol kontrol interaktif seperti berhenti, ulangi lagi dan lanjutkan pada sebuah video guna meningkatkan kemampuan prosedural anak (Schwan, S., Riempp, 2004). Serta pemberian kuis interaktif dimana peserta didik akan menjawab dengan memilih sendiri jawaban dari beberapa pilihan yang telah disediakan.

Bentuk media yakni video juga sebagai pembanding utama dalam pengembangan media ini. Pemilihan materi circular diagram flow dinilai sesuai dengan media pembelajaran video instruksional interaktif yang fokus pada prosedural. Video pembelajaran yang bersifat step by step juga ternyata memberikan dampak lebih baik dalam hasil belajar (Nazari et al., 2020).

Dengan demikian tujuan dari penelitian pengembangan ini adalah mengembangkan media pembelajaran instruksional interaktif dengan konten yang fokus pada tahapan proses circular diagram flow. Dimana media pembelajaran ini sangat penting untuk meningkatkan pemahaman peserta didik serta proses inkuiri mereka.

\section{METODE PENELITIAN}

Penelitian Pengembangan (R\&D) dipilih sebagai dasar penelitian yang akan dilakukan oleh peneliti. Adapun model yang digunakan adalah model Plomp (Kreano, 2012). Seperti yang terlihat pada gambar 1.

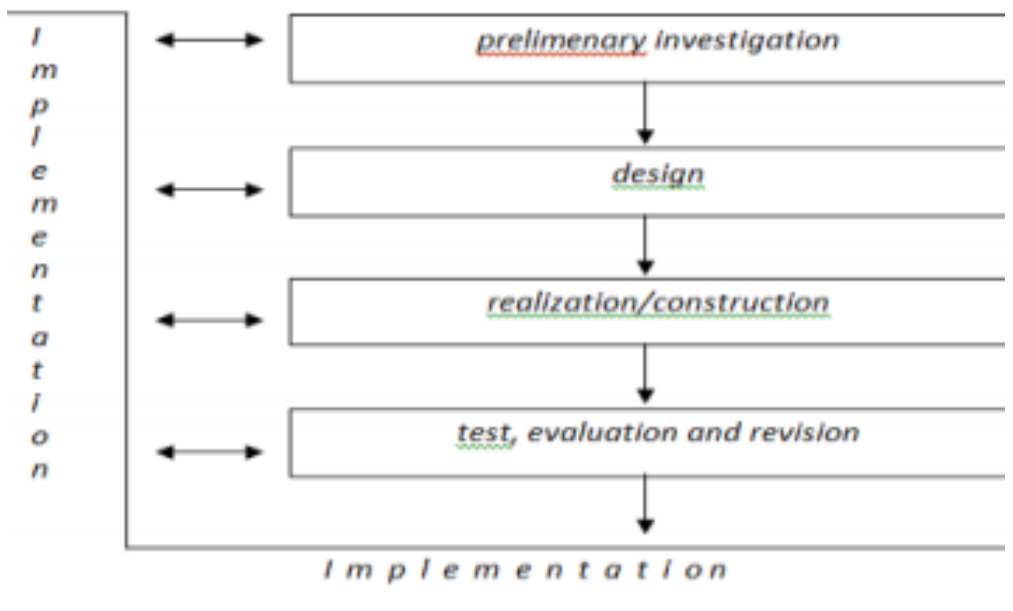

\section{Gambar 1. Tahapan penelitian menurut Plomp}

Dikarenakan berbagai keterbatasan, penelitian ini hanya mengambil 4 tahap dari 5 tahapan menurut Plomp. Diantaranya yaitu 1) investigasi awal; 2) desain produk merupakan; 3) pada tahap ini pemecahan dibuat; 4) tes, evaluasi, dan revisi. 
1525 Pengembangan Media Pembelajaran Video Instruksional Interaktif Pada Mata Pelajaran Ekonomi Kiranda Yuni Setyoningtyas, Muhammad Abdul Ghofur

DOI: https://doi.org/10.31004/edukatif.v3i4.601

Penelitian ini menggunakan instrumen diantaranya : 1) Hasil belajar (Pretest - Posttest) yang bertujuan untuk mengetahui tolok ukur keberhasilan dalam pengembangan produk. Serta untuk mengetahui peningkatan pemahaman terkait materi circular diagram flow pada peserta didik; 2) kuisioner; 3) lembar validasi. Pre-test merupakan suatu test yang dilakukan kepada peserta didik sebelum menggunakan media, Post-test merupakan suatu test yang dilakukan setelah peserta didik menggunakan media. Suryabrata (2007:102) menjelaskan bahwa desain penelitian One Group Pretest - Postest Design bertujuan untuk memberikan landasan terhadap perbedaan prestasi peserta didik yang sama sebelum dan sesudah dikenai $\mathrm{X}$ (experimental treatment).

Subjek uji coba produk adalah 15 peserta didik dari X IPS SMA Muhammadiyah Nganjuk. Uji coba terbatas ini adalah bagian dari tahap pengembangan. Instrumen Pretest - Posttest, dan lembar kuisioner respon juga divalidasi oleh ahli di bidangnya.

Semua data kemudian dianalisis. Tingkat pemahaman peserta didik terhadap materi circular diagram flow akan diukur menggunakan soal Pretest - Posttest. Uji t-test akan digunakan untuk mengetahui peningkatan pemahaman pada peserta didik.

\section{HASIL DAN PEMBAHASAN PENELITIAN}

Media pembelajaran video interaktif akan menjadi hasil akhir pada penelitian ini dimana produk ini akan dilengkapi dengan kuis yang ada pada media. Proses pengembangan produk ini dilakukan melalui beberapa tahapan sampai terwujudnya produk media pembelajaran video interaktif.

\section{Tahap Investigasi Awal}

Sebagai bahan pelengkap pembelajaran, media video interaktif ini membutuhkan informasi mengenai kesulitan belajar peserta didik. Untuk itulah dibutuhkan kegiatan observasi yang dilakukan di SMA Muhammadiyah Nganjuk sebagai bahan acuan yang digunakan untuk membuat media pembelajaran. Pada materi ekonomi mengenai circular diagram flow ditemukan beberapa kesulitan belajar yaitu: keterbatasan media dan sumber pembelajaran, yang mana guru menggunakan sumber belajar berupa buku LKS dan media belajar powerpoint. Penggunaan media pembelajaran tersebut sebenarnya sudah cukup baik mengingat pembelajaran selesai pada waktu yang telah ditentukan, namun hasil belajar yang didapatkan oleh peserta didik masih terbilang kurang, hal ini kemungkinan dikarenakan kurangnya perhatian peserta didik saat pembelajaran berlangsung. Materi circular diagram flow memiliki karakteristik yang membutuhkan visualisasi yang menarik serta proses gerak. Penggunaan video dalam media yang dikembangkan ini akan diperkaya dengan visualisasi materi dengan menyertakan animasi dan panah yang bergerak sesuai dengan penjelasan untuk dapat memperjelas proses arus kegiatan.

Berdasarkan tanya-jawab yang dilakukan, baik pendidik maupun peserta didik sangat mengharapkan pembelajaran ekonomi pada materi circular diagram flow dibuat menarik dan tidak monoton. Menurut pendidik pihak sekolah sebenarnya sangat mendukung untuk penggunaan media pembelajaran akan tetapi terkendala di media yang interaktif. Untuk membuat peserta didik secara aktif terlibat dalam pembelajaran adalah dengan menggunakan media interaktif. Untuk itu peneliti melakukan pengembangan terhadap media pembelajaran video dengan menambahkan tombol interaktif dapat melibatkan peserta didik secara langsung

Pada pembelajaran ekonomi materi circular diagram flow akan ditambahkan tombol interaktif berupa pemberian kuis di beberapa bagian materi yang ditujukan untuk memunculkan interaksi antara peserta didik dan proses pembelajaran secara langsung.

Penelitian ini berfokus pada mengembangkan media pembelajaran video interaktif. Dengan bentuk interaktifnya ialah kuis pada bagian-bagian materi serta feedback yang diberikan ketika peserta didik menjawab kuis tersebut. Adanya video yang akan menjelaskan materi dengan visualisasi yang menarik dan beberapa pengulangan guna mendukung belajar mandiri pada peserta didik. 
1526 Pengembangan Media Pembelajaran Video Instruksional Interaktif Pada Mata Pelajaran Ekonomi Kiranda Yuni Setyoningtyas, Muhammad Abdul Ghofur

DOI: https://doi.org/10.31004/edukatif.v3i4.601

\section{Tahap Design}

Pada tahap design peneliti menggunakan media H5P.com yang mana merupakan laman untuk membantu pembuatan video interaktif. Peneliti memilih media ini karena memudahkan peneliti untuk menyatukan tombol interaktif kuis dengan video yang akan disajikan kepada peserta didik. Penggunaan laman H5P.com ini memungkinkan hasil media pembelajaran berupa link. Laman H5P.com ini juga memungkinkan guru untuk memberikan feedback terhadap jawaban yang diberikan oleh peserta didik baik itu jawaban benar maupun jawaban yang salah. Gambaran awal untuk desain yang dibuat menggunakan H5P.com dapat dilihat melalui gambar 1 dan gambar 2 berikut.

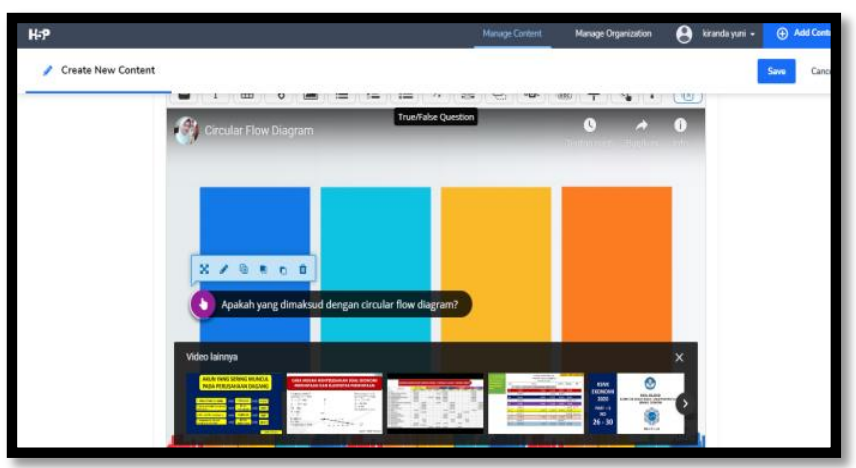

Gambar 2. Letak pertanyaan pada bagian awal

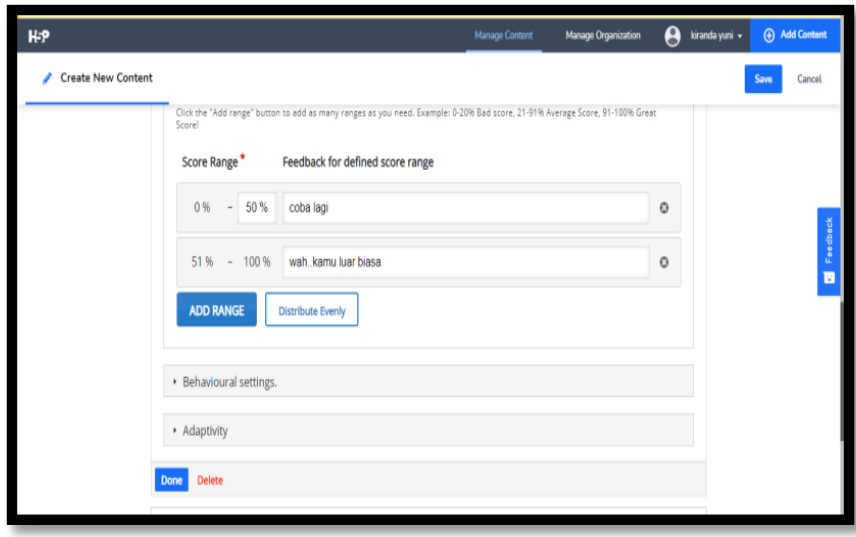

Gambar 3. Pemberian umpan balik

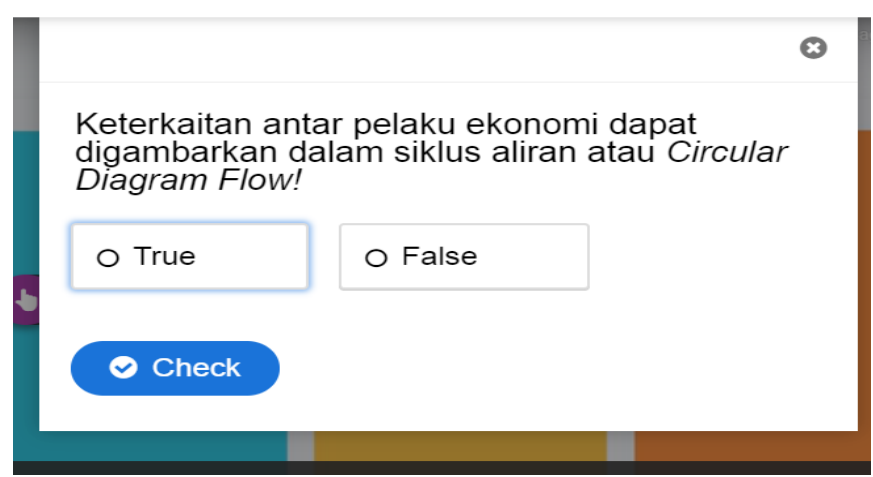

Gambar 4. Contoh bentuk soal true/false 
1527 Pengembangan Media Pembelajaran Video Instruksional Interaktif Pada Mata Pelajaran Ekonomi Kiranda Yuni Setyoningtyas, Muhammad Abdul Ghofur

DOI: https://doi.org/10.31004/edukatif.v3i4.601
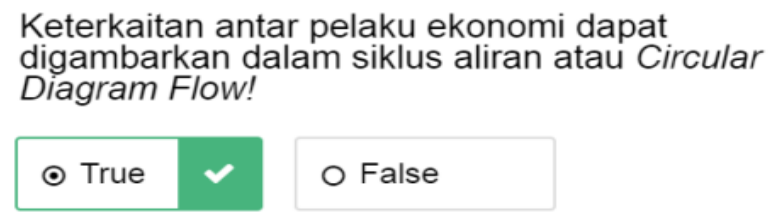

Jangan Lupa Mencatat!

\section{Gambar 5. Pemberian umpan balik ketika menjawab benar}

Media pembelajaran video interaktif yang akan dikembangkan ini memiliki beberapa fitur interaktif yakni berbagai bentuk kuis seperti multiple choice, truelfalse question, dan fill in the blanks. Beberapa jenis model pertanyaan ini ditujukan agar peserta didik tidak bosan dalam memahami materi dan selalu merasa tertantang untuk menjawab pertanyaan selanjutnya. Hal ini didapatkan dari uji coba pada teman peneliti dan beberapa peserta didik di SMA Muhammadiyah Nganjuk.

Media pembelajaran awal yang telah dikembangkan akan diuji coba kan kepada guru ekonomi di SMA Muhammadiyah Nganjuk serta mahasiswa Jurusan Pendidikan Ekonomi dan mahasiswa Jurusan Pendidikan Kimia untuk mengetahui kekurangan dan kelebihan dari pengembangan media yang telah dihasilkan oleh peneliti. Hasilnya materi yang disajikan terlihat biasa dan standar seperti media pembelajaran yang lain, akan tetapi penambahan fitur interaktif yakni tombol kuis dirasa sangat menarik dan menjadi pancingan agar peserta didik tidak kehilangan fokus. Kuis yang disediakan juga muncul di saat- saat yang tepat, sehingga mampu memperkuat pemahaman peserta didik terkait materi yang dijelaskan. Fitur kuis dengan berbagai macam model pertanyaan menjadi daya tarik yang paling kuat bagi guru ekonomi di SMA Muhammadiyah tersebut karena mampu memperkuat konsep yang diterima oleh peserta didik melalui materi yang disampaikan di video tersebut. Media pembelajaran awal yang telah dikembangkan akan diuji coba kan kepada guru ekonomi di SMA Muhammadiyah Nganjuk serta mahasiswa Jurusan Pendidikan Ekonomi dan mahasiswa Jurusan Pendidikan Kimia untuk mengetahui kekurangan dan kelebihan dari pengembangan media yang telah dihasilkan oleh peneliti. Hasilnya materi yang disajikan terlihat biasa dan standar seperti media pembelajaran yang lain, akan tetapi penambahan fitur interaktif yakni tombol kuis dirasa sangat menarik dan menjadi pancingan agar peserta didik tidak kehilangan fokus. Kuis yang disediakan juga muncul di saat- saat yang tepat, sehingga mampu memperkuat pemahaman peserta didik terkait materi yang dijelaskan. Fitur kuis dengan berbagai macam model pertanyaan menjadi daya tarik yang paling kuat bagi guru ekonomi di SMA Muhammadiyah tersebut karena mampu memperkuat konsep yang diterima oleh peserta didik melalui materi yang disampaikan di video tersebut.

Guru ekonomi menyarankan untuk menambahkan tombol catatan yang bertujuan untuk menjelaskan beberapa kata-kata yang luput dari penjelasan narator pada video. Sekaligus menambah jenis interaksi pada video sehingga bukan hanya menjawab soal akan tetapi peserta didik juga diajak untuk mencatat istilah-istilah yang sulit dipahami.

\section{Fase Realisasai/Kontruksi}

Fase ini merupakan lanjutan dari fase sebelumnya yaitu fase design. Pada tahapan realisasi/kontruksi, media pembelajaran video interaktif akan dikembangkan secara keseluruhan yang membahas mengenai circular diagram flow. Setelah tahap ini selesai akan dilakukan tahap selanjutnya yakni evaluasi, revisi, dan validasi. 
1528 Pengembangan Media Pembelajaran Video Instruksional Interaktif Pada Mata Pelajaran Ekonomi Kiranda Yuni Setyoningtyas, Muhammad Abdul Ghofur

DOI: https://doi.org/10.31004/edukatif.v3i4.601

Materi video yang digunakan pada media yang dikembangkan ini mengambil dari salah satu video yang tersedia di youtube. Video yang digunakan telah terlebih dahulu diseleksi dengan melihat keseluruhan isi yang memiliki kesesuaian dengan kebutuhan peserta didik di SMA Muhammadiyah Nganjuk. Agar tidak melanggar hak cipta, sebelum mengedit video pada laman H5P.com telah dipastikan mencantumkan sumber video yang asli.

Dengan adanya tambahan dan komentar yang diberikan teman dan guru ekonomi di SMA Muhammadiyah Nganjuk. Video yang akan dikembangkan akan berisi beberapa fitur di antaranya materi, tombol interaksi kuis yang terdiri dari 5 bentuk pertanyaan : true/false question, multiple choice dan fill in the blank. Serta tombol catatan yang ditujukan untuk memberikan penjelasan tertulis dari beberapa istilah yang tidak dijelaskan dalam video.

\section{Fase Evaluasi, Tes dan Revisi}

Pada tahap ini media yang dikembangkan dan dihasilkan akan dipertimbangkan kualitasnya. Pendapat dari mahasiswa yang telah mencoba media dan guru ekonomi di SMA Muhammadiyah akan ditambahkan pada tahap ini. Penambahan tombol catatan yang bertujuan untuk menjelaskan istilah yang tidak dijelaskan pada video. Produk media yang dikembangkan secara keseluruhan membahas mengenai circular diagram flow.

Hasil dari revisi dan penambahan masukan yang diberikan oleh guru dan beberapa teman peneliti maka hasil media yang telah dikembangkan dapat dilihat dalam link berikut https://kirandayuni14.h5p.com/content/1291318403744119689.

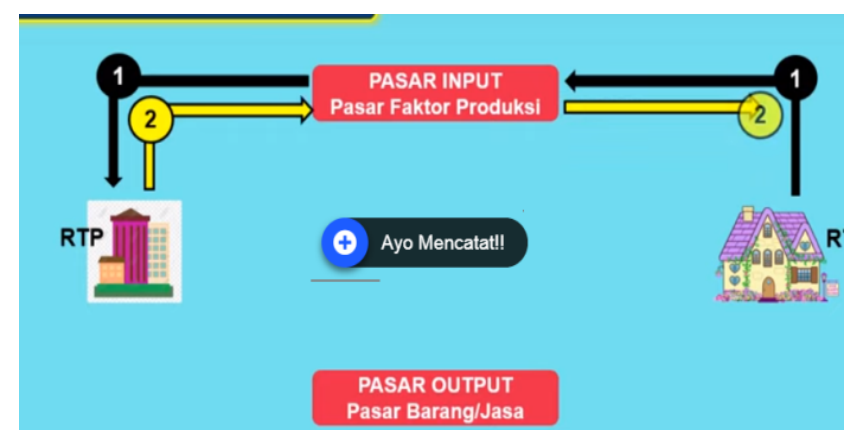

Gambar 6. Tombol catatan

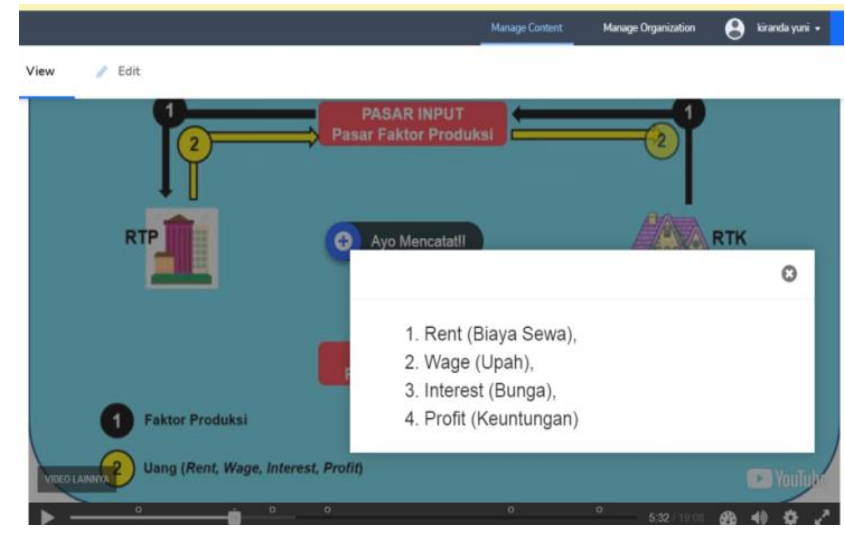

Gambar 7. Tampilan apabila tombol catatan di buka

\section{Uji Kevalidan butir soal Pretest dan Posttest}

Pretest dan posttest digunakan untuk mengetahui tingkat perubahan pemahaman pada peserta didik saat sebelum dan sesudah menggunakan media pembelajaran tersebut. Instrumen butir soal yang digunakan telah dilakukan uji validitas dan reliabel. Hasil validitas terdapat 14 soal dari 20 soal yang memiliki nilai valid. Sedangkan 6 di antaranya tidak valid. 
1529 Pengembangan Media Pembelajaran Video Instruksional Interaktif Pada Mata Pelajaran Ekonomi Kiranda Yuni Setyoningtyas, Muhammad Abdul Ghofur

DOI: https://doi.org/10.31004/edukatif.v3i4.601

Tabel 1

Validitas soal

\begin{tabular}{lll}
\hline Nomor soal & Kriteria & Jumlah \\
\hline $1,2,3,4,5,6,8,10,11,14,16,18,19,20$ & Valid & 14 \\
& & \\
\hline $7,9,12,13,15,17$ & Tidak & 6 \\
& Valid & \\
\hline Total & & 20 \\
\hline
\end{tabular}

Tabel 2

Reliabilitas Soal

\begin{tabular}{|c|c|}
\hline Nomor soal & Cronbach's Alpha \\
\hline Soal1 & .905 \\
\hline Soal2 & .896 \\
\hline Soal3 & .893 \\
\hline Soal4 & .896 \\
\hline Soal5 & .908 \\
\hline Soal6 & .911 \\
\hline Soal8 & .905 \\
\hline Soal10 & .901 \\
\hline Soal11 & .910 \\
\hline Soal14 & .898 \\
\hline Soal16 & .898 \\
\hline Soal18 & .903 \\
\hline Soal19 & .900 \\
\hline Soal20 & .905 \\
\hline
\end{tabular}

\section{Pemahaman Peserta Didik Setelah Penggunaan Media Pembelajaran Video Interaktif Pada Mata Pelajaran Ekonomi Sub BAB Circular Diagram Flow}

\section{Uji Normalitas}

Untuk menguji persebaran data maka dilakukan uji normalitas. Untuk melihat apakah distribusi data bersifat normal ataukah tidak dapat dilihat dari nilai signifikansinya. Apabila nilai signifikansi $>0,05$ maka pendistribusian data berjalan normal, sebaliknya jika nilai signifikansinya bernilai $<0,05$ maka pendistribusian data tidak berjalan normal.

Berdasarkan tabel 4. Menginformasikan bahwa seluruh data hasil belajar pretest dan posttest terdistribusi normal karena memiliki nilai signifikansi 0,633.

\section{Uji t}

Untuk mengetahui peningkatan pemahaman peserta didik dalam menggunakan media pembelajaran yang telah dikembangkan, maka akan digunakan uji t (Paired sample test) yang melibatkan hasil dari nilai pretest dan post-test. Untuk melihat keefektifan media yang dihasilkan dalam meningkatkan pemahaman peserta didik dilihat dari nilai signifikansi pada uji t. Apabila bernilai $<0,05$ maka media pembelajaran tersebut efektif. Sedangkan bila $>0,05$ maka media pembelajaran tersebut tidak efektif 
1530 Pengembangan Media Pembelajaran Video Instruksional Interaktif Pada Mata Pelajaran Ekonomi Kiranda Yuni Setyoningtyas, Muhammad Abdul Ghofur

DOI: https://doi.org/10.31004/edukatif.v3i4.601

Tabel 3

Uji Normalitas

\begin{tabular}{llr}
\hline \multicolumn{2}{c}{ One-Sample Kolmogorov-Smirnov Test } & Unstandardized Residual \\
\hline $\mathrm{N}$ & & 15 \\
\hline Normal Parameters $^{a}$ & Mean & .0000000 \\
\cline { 2 - 3 } & Std. Deviation & 8.20876489 \\
\hline Most Extreme Differences & Absolute & .193 \\
\cline { 2 - 3 } & Positive & .146 \\
\cline { 2 - 3 } & Negative &. .193 \\
\hline Kolmogorov-Smirnov Z & & .747 \\
\hline Asymp. Sig. (2-tailed) & & .633 \\
\hline a. Test distribution is Normal. & \\
\hline
\end{tabular}

Tabel 4

Uji Paired Sample Test

\begin{tabular}{|c|c|c|c|c|c|c|c|c|c|}
\hline & & & & & & & & & \\
\hline & & & & aired Diffe & ences & & & & \\
\hline & & Mean & $\begin{array}{c}\text { Std. } \\
\text { Deviation }\end{array}$ & $\begin{array}{c}\text { Std. Error } \\
\text { Mean }\end{array}$ & $\begin{array}{r}95 \% \text { Co } \\
\text { Intervo } \\
\text { Diffe }\end{array}$ & $\begin{array}{l}\text { fidence } \\
\text { of the } \\
\text { ence }\end{array}$ & $t$ & $d f$ & Sig. (2-tailed) \\
\hline & & & & & Lower & Upper & & & \\
\hline Pair 1 & $\begin{array}{l}\text { Pretest - } \\
\text { Posttest }\end{array}$ & 32.667 & 12.799 & 3.305 & -39.754 & -25.579 & -9.885 & 14 & .000 \\
\hline
\end{tabular}

Berdasarkan tabel 5 menginformasikan bahwa hasil belajar terdapat perbedaan pada hasil tes sebelum dan sesudah menggunakan media. Hal ini berarti bahwa media pembelajaran video interaktif efektif untuk meningkatkan pemahaman peserta didik karena memperoleh nilai signifikansi kurang dari 0,05.

\section{Gain Score}

Perhitungan nilai gain score ditujukan untuk melihat peningkatan pemahaman peserta didik. Dengan cara membandingkan nilai pretest dan posttest pada penggunaan media pembelajaran video interaktif. Pemahaman akan dinilai meningkat apabila nilai gain score $>0,3$. Pada tabel 3. Menginformasikan bahwa terjadi peningkatan pemahaman pada peserta didik dengan memperoleh hasil gain score 0,48.

Tabel 5

Hasil Gain Score

\begin{tabular}{lllll} 
No & Nama & $\begin{array}{c}\text { Pre } \\
\text { test }\end{array}$ & $\begin{array}{l}\text { Post } \\
\text { test }\end{array}$ & Gain Score \\
\hline 1 & S1 & 60 & 95 & 0,6 \\
\hline 2 & S2 & 60 & 95 & 0,6 \\
\hline 3 & S3 & 30 & 55 & 0,3 \\
\hline 4 & S4 & 45 & 95 & 0,45 \\
\hline 5 & S5 & 35 & 75 & 0,35 \\
\hline 6 & S6 & 40 & 80 & 0,4 \\
\hline 7 & S7 & 60 & 85 & 0,6 \\
\hline 8 & S 8 & 50 & 90 & 0,5 \\
\hline 9 & S9 & 50 & 75 & 0,5 \\
\hline 10 & S10 & 35 & 80 & 0,35 \\
\hline
\end{tabular}

Edukatif : Jurnal Ilmu Pendidikan Vol 3 No 4 Tahun 2021 p-ISSN 2656-8063 e-ISSN 2656-8071 
1531 Pengembangan Media Pembelajaran Video Instruksional Interaktif Pada Mata Pelajaran Ekonomi Kiranda Yuni Setyoningtyas, Muhammad Abdul Ghofur

DOI: https://doi.org/10.31004/edukatif.v3i4.601

\begin{tabular}{lllll}
\hline No & Nama & $\begin{array}{c}\text { Pre } \\
\text { test }\end{array}$ & $\begin{array}{l}\text { Post } \\
\text { test }\end{array}$ & Gain Score \\
\hline 11 & S11 & 35 & 75 & 0,35 \\
\hline 12 & S12 & 55 & 90 & 0,55 \\
\hline 13 & S13 & 55 & 70 & 0,55 \\
\hline 14 & S14 & 45 & 95 & 0,45 \\
\hline 15 & S15 & 60 & 90 & 0,6 \\
\hline Jumlah & $\mathbf{7 1 5}$ & $\mathbf{1 2 4 5}$ & $\mathbf{7 , 1 5}$ \\
\hline Rata - Rata & $\mathbf{4 7 , 7}$ & $\mathbf{8 3}$ & $\mathbf{0 , 4 8}$ \\
\hline
\end{tabular}

\section{Analisis Respons Peserta didik}

Respons peserta didik dan guru dalam penggunaan media pembelajaran video interaktif diukur menggunakan skala likert. Media akan dinilai dengan skor 1 sampai dengan 5.

Tabel 6

Tabel Skor penilaian Skala Likert

\begin{tabular}{ll}
\hline Skor & Keterangan \\
\hline 5 & Sangat Baik \\
\hline 4 & Baik \\
\hline 3 & Cukup \\
\hline 2 & Kurang \\
\hline 1 & Sangat Kurang \\
\hline
\end{tabular}

Hasil Respons peserta didik dan pengajar adalah 90\% dari 15 peserta didik dan 5 pendidik, 18 di antaranya mengelompok kan media pembelajaran video interaktif baik - sangat baik untuk digunakan dalam pembelajaran. Sebagaimana penelitian yang dilakukan oleh Akmaliyah (2013) yang memperoleh respons sebesar 86,67\% Respons positif terhadap pengembangan media pembelajaran interaktif yang dikembangkan. Begitu pula penelitian yang dilakukan di Universitas Seville (Spanyol) pada proses kegiatan ekonomi makro, dengan menggunakan media video dapat meningkatkan nilai tes mahasiswanya menjadi lebih tinggi (Expósito et al., 2020).

Dengan demikian media pembelajaran ini setidaknya bisa digunakan sebagai media untuk melakukan recalling materi yang telah dipelajari sebelumya (Obagah \& Brisibe, 2017). Sehingga akan lebih lama tersimpan dalam memori jangka pendek, serta berpeluang masuk dalam memori jangka panjang siswa. Untuk pembelajaran mandiri video interaktif ini dapat digunakan sebagai media belajar individu maupun berkelompok sehingga meningkatkan self-directed learning dan kemandirian belajar peserta didik (Mohd Saiboon et al., 2021), (Singer, L. M., \& Alexander, 2017).

Dari hasil uji coba terbatas ini ditemukan beberapa keterbatasan produk media pembelajaran ini. Keterbatasan ini diantaranya adalah : (1) media video interaktif ini butuh alat pendukung yakni headset/headphone agar peserta didik bisa fokus pada video; (2) kuis yang ada pada video tidak bisa merekam skor hasil jawaban peserta didik, sehingga sifatnya tidak bisa mengevaluasi hasil pembelajaran yang ada dalam video, namun masih efektif untuk recalling yang tidak membosankan; (3) produk yang dikembangkan bersifat online dan cenderung mengalami proses loading yang cukup lama; (4) media pembelajaran video interaktif kurang maksimal tanpa kehadiran guru.

Dari hasil penelitian pengembangan ini masih perlu dilakukan pengujian yang lebih luas untuk mendapatkan informasi yang lebih banyak demi pengembangan yang lebih baik. Dari hasil penelitian ini pengembangan video pembelajaran interaktif ini maka penelitian-penelitian selanjutnya perlu untuk dilakukan terutama untuk menggali bagaimana penerapannya dalam beberapa desain pembelajaran serta karakteristik peserta didik. 
1532 Pengembangan Media Pembelajaran Video Instruksional Interaktif Pada Mata Pelajaran Ekonomi Kiranda Yuni Setyoningtyas, Muhammad Abdul Ghofur

DOI: https://doi.org/10.31004/edukatif.v3i4.601

\section{KESIMPULAN}

Dari hasil uji coba terbatas yang dilakukan peneliti dimana merupakan bagian dari tahapan pengembangan diperoleh hasil yang baik. Pemahaman peserta didik yang relatif meningkat. Respons peserta didik dan pendidik juga sangat baik dalam hal penggunaan media video interaktif ini. Media pembelajaran interaktif ini dapat digunakan sebagai media pembelajaran mandiri, recalling, dan merangsang proses inkuiri peserta didik. Sebelum diterapkan ke dalam pembelajaran media ini masih membutuhkan banyak masukan dan saran dari pengguna agar menjadi media video interaktif layak dapat dikembangkan menjadi lebih baik

\section{DAFTAR PUSTAKA}

Agustriana, E., . S. B., \& . W. (2014). Efektivitas Penggunaan Video Pembelajaran Untuk Meningkatkan Hasil Belajar Ekonomi Siswa SMA. Jurnal Pendidikan dan Pembelajaran Khatulistiwa, 3(8). Diambil dari https://jurnal.untan.ac.id/index.php/jpdpb/article/view/6657

Alhafidz, M. R. L., Haryono, A., \& Program, E. E. (2018). Pengembangan mobile learning berbasis android sebagai media pembelajaran ekonomi, 11(2), 118-124.

Arsyad, A. (2011). Media Pembelajaran. Jakarta: Rajawali Pers.

Daraban, B. (2010). Introducing the Circular Flow Diagram to Business Students. Journal of Education for Business, 85(5), 274-279. https://doi.org/10.1080/08832320903449527

Diah, I., \& Nita, S. (2018). Pembuatan Video Sebagai Media Pembelajaranuntuk Meningkatkan Pemahaman Mahasiswa. Journal of Computer and Information Technology, 1(2), 68-75.

Expósito, A., Sánchez-Rivas, J., Gómez-Calero, M. P., \& Pablo-Romero, M. P. (2020). Examining the use of instructional video clips for teaching macroeconomics. Computers and Education, 144(September 2019). https://doi.org/10.1016/j.compedu.2019.103709

Fleck, B. K. B., Richmond, A. S., \& Hussey, H. D. (2013). Using social media to enhance instruction in higher education. Research Perspectives and Best Practices in Educational Technology Integration, (January 2013), 217-241. https://doi.org/10.4018/978-1-4666-2988-2.ch012

Furi, U. L., \& Mustaji, N. (2017). Pengembangan Media Video Mata Pelajaran Komposisi Foto Digital Bagi Siswa Kelas Xi Multimedia Di Sekolah Menengah Kejuruan. Kwangsan: Jurnal Teknologi Pendidikan, 5(2), 91-100. https://doi.org/https://doi.org/10.31800/jtp.kw.v5n2.p91--100

Ghofur, M. A., \& Wahjoedi, W. (2018). Preferensi Sumber Belajar Online Mahasiswa Pendidikan Ekonomi. Jurnal Ekonomi Pendidikan dan Kewirausahaan, 6(1), 105-114. https://doi.org/10.26740/jepk.v6n1.p105-114

Hafizh, M. (2017). Jurusan akuntansi fakultas ekonomi universitas negeri semarang 2015. Jurnal Akuntansi.

Ikea. (2017). Ikea Pax Wardrobe with hinged doors assembly instructions.No Title. Diambil dari https://www.youtube.com/watch? $\mathrm{v}^{1 / 4 \mathrm{tTeI}} \mathrm{FSBqYw}$

Imaniya, A., Ulfah, M., Rosyid, R., \& Belajar, H. (2016). Penggunaan media video dalam pembelajaran ekonomi studi eksperimen SMA. Jurnal Pendidikan dan Pembelajaran Khatulistiwa, 5(1), 1-10.

Kreano, J. (2012). Desain Model Pengembangan Perangkat Pembelajaran Matematika, 3.

Marks, M., \& Kotula, G. (2009). Using the Circular Flow of Income Model to Teach Economics in the Middle School Classroom. The Social Studies, 100(5), 233-242. https://doi.org/10.1080/00377990903221939

Maulidiyah, S. (2018). Penerapan Metode Sosiodrama Dengan Media Circular Flow Diagram Unuk Meningkatkan Keaktifan Peserta Didik Pada Mata Pelajaran IPS Materi Kegiatan Ekonomi. Institut Agama Islam Negeri Salatiga.

Mohd Saiboon, I., Musni, N., Daud, N., Shamsuddin, N. S., Jaafar, M. J., Hamzah, F. A., \& Abu Bakar, A. (2021). Effectiveness of Self-Directed Small-Group-Learning Against Self-Directed Individual- 
1533 Pengembangan Media Pembelajaran Video Instruksional Interaktif Pada Mata Pelajaran Ekonomi Kiranda Yuni Setyoningtyas, Muhammad Abdul Ghofur

DOI: https://doi.org/10.31004/edukatif.v3i4.601

Learning Using Self-Instructional-Video in Performing Critical Emergency Procedures Among Medical Students in Malaysia: A Single-Blinded Randomized Controlled Study. Clinical Simulation in Nursing. https://doi.org/10.1016/j.ecns.2021.02.006

Nazari, T., van de Graaf, F. W., Dankbaar, M. E. W., Lange, J. F., van Merriënboer, J. J. G., \& Wiggers, T. (2020). One Step at a Time: Step by Step Versus Continuous Video-Based Learning to Prepare Medical Students for Performing Surgical Procedures. Journal of Surgical Education, 77(4), 779-787. https://doi.org/10.1016/j.jsurg.2020.02.020

Obagah, R. R., \& Brisibe, W. G. (2017). The Effectiveness of Instructional Videos in Enhancing Learning Experience of Architecture Students in Design and Drawing Courses: A Case Study of Rivers State University, Port-Harcourt. International Journal of Education and Research, 5(11), 33-46.

Revangga, A. (2015). Peningkatan Pemahaman Konsep Circular Flow Diagram Melalui Model Pembelajaran Role Playing Berbantuan Media Monopoli Pada Siswa Kelas X Lintas Minat-2 SMA N 1 Bangsri. Universitas Negeri Semarang.

Schwan, S., Riempp, R. (2004). The Cognitive Benefits of Interactive Videos: learning to tie nautical knots. Learn. Instruct., 14, 293-305.

Singer, L. M., \& Alexander, P. A. (2017). Reading across mediums: Effects of reading digital and print texts on comprehension and calibration. The Journal of Experimental Education, 85, 155-172.

Sudarman, Sugeng, H. (2018). Development of Interactive Infographic Learning Multimedia on Study Methodology Study Course of Economic Education Program of Mulawarman University. JURNAL PENDIDIKAN DAN PEMBELAJARAN, 25(2), 51-64.

Sukiman. (2012). Pengembangan Media Pembelajaran. (A. Salmulloh, Ed.) (1 ed.). Yogyakarta: PT Pustaka Insan Mandiri.

Tarchi, C., Zaccoletti, S., \& Mason, L. (2021). Learning from text, video, or subtitles: A comparative analysis. Computers and Education, 160(September 2020), 104034. https://doi.org/10.1016/j.compedu.2020.104034

Ten Hove, P., \& van der Meij, H. (2015). Like it or not. What characterizes YouTube's more popular instructional videos? Technical Communication. 62, 1, 48-62.

Whatley, J., \& Ahmad, A. (2007). Using Video to Record Summary Lectures to Aid Students' Revision. Interdisciplinary Journal of e-Skills and Lifelong Learning, 3(January 2007), 185-196. https://doi.org/10.28945/393

Yoon, M., Lee, J., \& Jo, I. H. (2021). Video learning analytics: Investigating behavioral patterns and learner clusters in video-based online learning. Internet and Higher Education, 50, 100806. https://doi.org/10.1016/j.iheduc.2021.100806

Yuliandari, Sintia \& Wahyudi, E. (2014). Pengembangan Media Pembelajaran Berbasis Multimedia Interaktif Pada Mata Pelajaran Ekonomi Materi Jurnal Penyesuaian Perusahaan Jasa. Jurnal Pendidikan Akuntansi (JPAK), 2(2), 1-9. 